\title{
The red wine polyphenol resveratrol reduces polycyclic aromatic hydrocarbon-induced DNA damage in MCF-10A cells
}

\author{
Hau Y. Leung ${ }^{1}$, Lai Hang Yung ${ }^{2}$, Guoli $\mathrm{Shi}^{3}$, A.-Lien $\mathrm{Lu}^{3}$ and Lai K. Leung ${ }^{1,4 *}$ \\ ${ }^{1}$ Food and Nutritional Sciences Programme, The Chinese University of Hong Kong, Shatin, NT, Hong Kong \\ ${ }^{2}$ Molecular Biotechnology Programme, The Chinese University of Hong Kong, Shatin, NT, Hong Kong \\ ${ }^{3}$ Department of Biochemistry and Molecular Biology, School of Medicine, Greenebaum Cancer Center, University of Maryland, \\ Baltimore, MD 21201, USA \\ ${ }^{4}$ Department of Biochemistry, The Chinese University of Hong Kong, Shatin, NT, Hong Kong
}

(Received 16 September 2008 - Revised 19 January 2009 - Accepted 24 April 2009 - First published online 8 October 2009)

Polycyclic aromatic hydrocarbons (PAH) are procarcinogens that can be commonly found in our food and environment. Upon biotransformation in our body system, they can cause DNA damage through the generation of genotoxic species and oxidative stress. Phase I and II enzymes are pivotal in the process of proximate carcinogen formation and elimination. Some dietary phytochemicals are strong inhibitors to the phase I enzymes. In the present study, we investigated the effect of the red wine compound resveratrol on DNA damage induced by PAH in a non-tumorigenic breast cell line MCF-10A. Resveratrol ranging from 1 to $5 \mu \mathrm{M}$ could significantly suppress the expressions of cytochrome P450 (CYP) 1A1, CYP1B1 and UDP-glucuronosyltransferase (UGT) 1A1 induced by 7,12-dimethylbenz[a]anthracene (DMBA). The comet assay indicated that DMBA introduced DNA damage to these cells, and co-treatment of resveratrol at 5 or $10 \mu \mathrm{M}$ could alleviate the damage. Further investigation illustrated that resveratrol reduced the binding of DMBA metabolites to DNA with no effect on DMBA-induced oxidative DNA damage. Since the phase II enzyme UGT1A1 was suppressed, the elimination of DMBA metabolites would not have contributed to the reduction in the DMBA metabolite-DNA binding. In summary, resveratrol might protect breast cells against PAH-induced DNA damage. The underlying mechanism was mediated by phase I enzyme suppression rather than phase II enzyme induction or oxidative DNA repair.

Cytochrome P450 1A1: Cytochrome P450 1B1: Comet assay: 8-Oxo-deoxyguanine: Resveratrol

Polycyclic aromatic hydrocarbons (PAH) are commonly found in our environment, and they can be isolated from diesel exhaust, barbequed meat, tobacco smoke, overheated cooking oil, etc $^{(1)}$. PAH are metabolised and transformed into adductforming compounds in the body. The significance of these environmental toxicants in breast cancer can be inferred from the increased presence of PAH-DNA adducts in human breast tumours ${ }^{(2)}$. This implies that the patients might be constantly exposed to PAH in their living environment and produced such disease.

Cytochrome P450 (CYP) 1A1 and CYP1B1 enzymes are responsible for the biotransformation of procarcinogens to genotoxic moieties $\mathrm{PAH}^{(3,4)}$. The importance of these CYP1 enzymes in PAH-induced carcinogenesis has been shown in two gene-knockout mouse models; benzo $[a]$ pyrene cannot induce CYP1A1 or cancer in aryl hydrocarbon receptor-null mice $^{(5)}$, and lower cancer incidence was observed in 7,12dimethylbenz $[a]$ anthracene (DMBA)-treated cyplbl knockout mice $^{(6)}$. The significance of CYP1 family enzymes in human breast cancer is not clear. Normal, tumour and histologically normal adjacent tissues of the breast express CYP1A1 and
CYP1B1 $1^{(7-10)}$. The inhibition of CYP1 enzymes appears to be beneficial in the prevention of DMBA-DNA adduct formation in vivo ${ }^{(11)}$ and in vitro ${ }^{(12)}$. Polymorphisms with higher activity of CYP1A1 appear to be a risk factor for breast cancer in African-Americans ${ }^{(13)}$; so are the polymorphisms of CYP1B1 in Asian women ${ }^{(14)}$.

Another enzyme which can be important in PAH-induced carcinogenesis is UDP-glucuronosyltransferase (UGT) $1 \mathrm{~A} 1$. UGT represent a major class of phase II drug-metabolising enzymes. They facilitate the elimination of non-polar xenobiotics and endogenous compounds through UDP-glucuronic acid conjugation ${ }^{(15,16)}$. UGT1A1 belongs to the family UGT1A, and it can metabolise bilirubin, xenobiotics, phenol and oestradiol $^{(17-19)}$. UGT1A1 can be effective in alleviating PAH-induced DNA damage and oestrogen-induced cell proliferation $^{(20)}$.

Resveratrol is a non-flavonoid phyto-oestrogen isolated from grapes. Previous study has revealed that resveratrol may inhibit CYP1A1 enzyme ${ }^{(21)}$ and may potentially block breast carcinogenesis by reducing DNA adduct formation. The notion has been supported by animal and

Abbreviations: CYP, cytochrome P450; DMBA, 7,12-dimethylbenz[a ]anthracene; Gmean, geometric mean; 8-oxodG, 8-oxodeoxyguanine; PAH, polycyclic aromatic hydrocarbons; Tris, 2-amino-2-hydroxymethyl-propane-1,3-diol; UGT, UDP-glucuronosyltransferase.

* Corresponding author: Dr Lai K. Leung, fax +852 26037732, email laikleung@cuhk.edu.hk 
cell models ${ }^{(22)}$. Diets with high resveratrol content are also associated with reduced breast cancer risk $^{(23,24)}$. As the phytocompound has drawn much attention in recent years, mechanistic studies are required for validating its health implications.

In the initiation stage of carcinogenesis, $\mathrm{PAH}$ can introduce DNA mutation by generating DNA damages by forming genotoxic metabolites and oxidative stress. Our defence system may up-regulate the expression of antioxidant and phase II enzymes to eliminate the toxicants and free radicals, which are the sources for DNA adduct-forming metabolites and oxidative DNA damage. Besides, some repair mechanisms are activated to counteract the DNA damage. In the present study, the effect of resveratrol on some of these pathways was investigated. The non-cancerous MCF-10A cells have normal mammary cell morphology, and are a preferred model for studying early events in carcinogenesis $^{(25)}$.

\section{Materials and methods}

\section{Chemicals}

${ }^{3}$ H-labelled DMBA was obtained from Amersham Pharmacia Biotech UK Ltd (Little Chalfont, Bucks, UK). Other reagents, if not stated, were purchased from Sigma Chemicals (St Louis, MO, USA).

\section{Cell culture}

MCF-10A cells (American Tissue Culture Collection, Rockville, MD, USA) were routinely cultured in Roswell Park Memorial Institute (RPMI) 1640 media (Sigma Chemicals), supplemented with $10 \%$ fetal bovine serum (Invitrogen Life Technologies, Rockville, MD, USA) and antibiotics (50 U penicillin/ml, $50 \mu \mathrm{g}$ streptomycin $/ \mathrm{ml})$, and incubated at $37^{\circ} \mathrm{C}$ and $5 \% \mathrm{CO}_{2}$. At $3 \mathrm{~d}$ before the experiment, the cultures were switched to RPMI-1640 phenol red-free media (Sigma Chemicals) and 5\% charcoal-dextran-treated fetal bovine serum (HyClone, Logan, UT, USA). With dimethylsulfoxide as the carrier solvent, sub-confluent cell cultures were treated with $2.5 \mu \mathrm{M}-\mathrm{DMBA}$ and resveratrol ranging from 1 to $10 \mu \mathrm{M}$ simultaneously. The final concentration of the solvent was $0 \cdot 1 \%(\mathrm{v} / \mathrm{v})$, and the control cultures received dimethylsulfoxide only. The 3-(4,5-dimethylthiazol-2-yl)-2,5-diphenyltetrazolium bromide assay did not reveal any significant difference in cell proliferation among the treatments from 24 to $72 \mathrm{~h}$ (data not shown).

\section{Measurement of 7,12-dimethylbenz[a ] anthracene-DNA adduct formation}

The assay was performed as previously described ${ }^{(26)}$ and was performed in a six-well plate. First, $5 \times 10^{5}$ cells were placed in each well and allowed to attach for $24 \mathrm{~h}$. They were treated with $\left[{ }^{3} \mathrm{H}\right] \mathrm{DMBA}(0 \cdot 1 \mu \mathrm{g} / \mathrm{ml})$. After $16 \mathrm{~h}$, cells were washed with cold PBS, trypsinised and pelleted. Cells were incubated on ice in a nuclei-separating buffer (10 mM-2-amino-2-hydroxymethylpropane-1,3-diol (Tris)-HCl, $\mathrm{pH} \quad 7 \cdot 5,320 \mathrm{~mm}$-sucrose, $5 \mathrm{~mm}$-magnesium chloride and $1 \%$ Triton $\mathrm{X}-100)$ to separate the nuclei, which were separated from cell debris by centrifugation at $4000 \mathrm{~g}$ for $10 \mathrm{~min}$ at $4{ }^{\circ} \mathrm{C}$. The nuclei were lysed using $400 \mu \mathrm{l}$ nuclei lysis buffer (1\% SDS in $0.5 \mathrm{M}$-Tris, $20 \mu \mathrm{M}-\mathrm{EDTA}$ and $10 \mathrm{~mm}-\mathrm{NaCl}, \mathrm{pH} 9)$ and then treated with $20 \mu \mathrm{l}$ proteinase $\mathrm{K}(20 \mathrm{mg} / \mathrm{ml})$ for $2 \mathrm{~h}$ at $48^{\circ} \mathrm{C}$. The samples were cooled at room temperature and residual proteins were precipitated by the addition of $150 \mu \mathrm{l}$ saturated $\mathrm{NaCl}$. The samples were centrifuged at $10000 \mathrm{~g}$ for $30 \mathrm{~min}$ at $4^{\circ} \mathrm{C}$, and genomic DNA was isolated from the supernatant fraction by ethanol precipitation and re-dissolved in autoclaved distilled water. DNA samples having an optical density $260 / 280 \mathrm{~nm}$ ratio larger than 1.9 were used for scintillation counting. Samples were mixed with $4 \mathrm{ml}$ cocktail in a vial and were subjected to scintillation counting.

\section{Comet assay}

A CometAssay ${ }^{\mathrm{TM}}$ Kit was ordered from Trevigen (Gaithersburg, MD, USA). Cells were placed in a six-well plate and allowed to attach for $24 \mathrm{~h}$. After simultaneous treatment of resveratrol $(0,1,5$ or $10 \mu \mathrm{M})$ and $2.5 \mu \mathrm{M}-\mathrm{DMBA}$ for $24 \mathrm{~h}$, cells were washed with PBS, trypsinised and pelleted. Control cultures received no DMBA or resveratrol. The cell pellet was re-suspended in PBS. Cells at $2 \times 10^{5}$ cells $/ \mathrm{ml}$ were combined with molten low-melting agarose at $42^{\circ} \mathrm{C}$ at $1: 10$. Then $75 \mu \mathrm{l}$ of the above mixture was pipetted and spread onto a CometSlide ${ }^{\mathrm{TM}}$. The slide was placed at $4^{\circ} \mathrm{C}$ in the dark for $30 \mathrm{~min}$ for better adherence and then immersed in pre-chilled lysis solution and kept at $4^{\circ} \mathrm{C}$ in the dark for $60 \mathrm{~min}$. The slides were left in alkaline solution for $60 \mathrm{~min}$ at room temperature in the dark before electrophoresis. Alkaline electrophoresis was performed at $4^{\circ} \mathrm{C}$ in the dark. Alkaline solution was added, sufficient to cover the samples. The electrophoresis was performed for $30 \mathrm{~min}$ at $25 \mathrm{~V}$. The slides were rinsed with double-distilled water after electrophoresis and immersed in $70 \%$ ethanol for $5 \mathrm{~min}$. The slides were dried in air and then stained with $50 \mu \mathrm{l} \mathrm{SYBR}$ green. After staining, DNA samples were viewed by using a Nikon TE2000 microscope with a wide band-pass green filter set (Chroma Technology Corp., San Jose, CA, USA). Images were saved from a camera attached and assessed by visual scoring on a five-point scale as described previously ${ }^{(27)}$. All cells within the scope were scored from 0 to 4 according to the tail length. Three slides per group were enumerated.

\section{Quantitative real-time polymerase chain reaction}

MCF-10A cells were seeded in a six-well plate for $1 \mathrm{~d}$ before treatment. The medium was removed, and cells were cultured in $2.5 \mu \mathrm{M}$-DMBA and $0,1,5$ or $10 \mu \mathrm{M}$-resveratrol administered simultaneously for $24 \mathrm{~h}$. Total RNA was extracted from the cells using TRIzol reagent (Invitrogen, Carlsbad, CA, USA). The concentration and purity of RNA were determined by absorbance at 260/280 nm. First, DNA strands were synthesised from $3 \mu \mathrm{g}$ total RNA using oligo-dT primers and Moloney murine leukaemia virus RT (USB Corporation, Cleveland, $\mathrm{OH}$, USA). Target fragments were quantified by real-time PCR, and a DNA Engine Opticon II (MJ Research, Inc., Waltham, MA, USA) was employed for this assay. Taqman/VIC minor groove binder probes and primers for CYP1A1, CYP1B1, UGT1A1 and glyceraldehyde-3-phosphate dehydrogenase (Assay-on-Demand ${ }^{\mathrm{TM}}$ ) and real-time PCR 
Taqman Universal PCR Master Mix were all obtained from Applied Biosystems. PCR reactions were set up as described in the protocol, which was validated by the manufacturer. Signals obtained for glyceraldehyde 3-phosphate dehydrogenase were used as a reference housekeeping gene to normalise the amount of total RNA amplified in each reaction. Relative gene expression data were analysed using the $2^{-\Delta \Delta C T}$ $\operatorname{method}^{(28)}$.

\section{Ethoxyresorufin-O-deethylase activity}

The assay method was performed as previously described ${ }^{(20)}$. In brief, MCF-10A cells in ninety-six-well plates were treated with $2.5 \mu \mathrm{M}$-DMBA and various concentrations of phytochemicals. The medium was then removed and the cells were washed twice by $100 \mu \mathrm{l}$ PBS. Ethoxyresorufin- $O$-deethylase activity, which is indicative of CYP1 enzyme activities, was determined. Then $100 \mu \mathrm{l}$ of $5 \mu \mathrm{M}$-ethoxyresorufin in PBS with $1.5 \mathrm{~mm}$-salicyclamide was added to each well, and incubated at $37^{\circ} \mathrm{C}$ for $15 \mathrm{~min}$. The reaction was stopped by $100 \mu \mathrm{l}$ ice-cold methanol, and the resorufin generated was measured by a FLUOstar Galaxy microplate reader (BMG Labtechnologies, Offenburg, Gemany) with an excitation of $544 \mathrm{~nm}$ and emission at $590 \mathrm{~nm}$.

\section{Oxidative DNA damage assay}

A fluorometric OxyDNA Assay Kit was obtained from Calbiochem (San Diego, CA, USA) and was carried out as described previously ${ }^{(29)}$. MCF-10A cells were cultured in a six-well plate. After $2 \cdot 5 \mu \mathrm{M}$-DMBA and $0,0 \cdot 1,1$ or $10 \mu \mathrm{M}$-resveratrol treatment, the cells were trypsinised, washed and suspended in Falcon culture tubes. Control cells received the solvent vehicle dimethylsulfoxide only. The cells were fixed with $1 \mathrm{ml}$ of $70 \%$ ethanol and stored at $4^{\circ} \mathrm{C}$ overnight. After fixing, the cells were washed twice and re-suspended in blocking solution for $1 \mathrm{~h}$ at $37^{\circ} \mathrm{C}$. The cells were incubated in fluorescein isothiocyanateconjugate solution in the dark for $1 \mathrm{~h}$ at room temperature. The cells were collected and re-suspended in fluorescenceactivated cell sorting (FACS) fluid. The amount of oxidised DNA was determined by FACSort ${ }^{\mathrm{TM}}$ flow cytometry with fluorescein isothiocyanate filter (BD Biosciences, San Jose, CA, USA), and 10000 cells were enumerated for each run.

\section{Preparation of oligonucleotide substrates}

The 19-mer oligonucleotide substrates required for activity assays were synthesised and purified as previously described $^{(30)}$. The sequences are as follows:

\section{Chang 179: 5'-GCAGAAGGCOAAATTCCTCG-3'; Chang68C: 5'-CCGAGGAATTCEGCCTTCTG-3',}

where $\mathrm{O}$ represents 8-oxodeoxyguanine (8-oxodG) and the bases at the matched site are underlined.

Heteroduplexes containing C/8-oxodG were constructed by annealing Chang $68 \mathrm{C}$ with Chang 179. Then 1 pmol of annealed duplexes was labelled at the $3^{\prime}$ or $5^{\prime}$ end as described by $\mathrm{Lu}^{(31)}$ and $\mathrm{Lu}$ et al. ${ }^{(32)}$. After being in-filled with a Klenow fragment with DNA polymerase I, the resulting blunt-end duplex DNA was $20 \mathrm{bp}$ in length.

\section{Assay of oxidative DNA repair activity}

Oxidative DNA repair measured as C/8-oxodG-DNA glycosylase activity was performed according to Hazra et al. ${ }^{(33)}$. A $25 \mu \mathrm{l}$ DNA binding reaction contained $20 \mu \mathrm{g}$ protein, $25 \mathrm{~mm}$-HEPES (pH 7.6), $50 \mathrm{~mm}-\mathrm{KCl}, 2.5 \mathrm{~mm}$-EDTA, 2 mM-dithiothreitol, $2.5 \%$ glycerol and $3.6 \mathrm{fmol}$ of C/8-oxodG-containing DNA labelled at the $5^{\prime}$ end of the 8 -oxodG-containing strand. The reactions were incubated at $37^{\circ} \mathrm{C}$ for $1 \mathrm{~h}$, and terminated by phenol-chloroform extraction and ethanol precipitation. Samples were dissolved in $3 \mu \mathrm{l}$ sequencing dye. After being heated at $90^{\circ} \mathrm{C}$ for $3 \mathrm{~min}$, samples were resolved on a $14 \%$ polyacrylamide-8.3 M-urea sequencing gel and analysed by autoradiograph.

\section{Statistical analysis}

A Prism ${ }^{\circledR} 3.0$ (GraphPad Software, Inc., San Diego, CA, USA) software package was utilised for statistical analysis. Results of all experiments were compared by ANOVA and Bonferroni's method for multiple comparisons. The level of significance was set at $P<0 \cdot 05$. For flow cytometry results and oxidative DNA repair assay, geometric means (Gmeans) of the distribution of oxidation DNA damage and optical density of the autoradiograph were obtained and compared.

\section{Results}

7,12-Dimethylbenz[a ]anthracene-induced cytochrome P450 1A1, cytochrome P450 1B1 and UDP-glucuronosyltransferase 1A1 mRNA expressions were suppressed by resveratrol

Surprisingly, UGT1A1 expression was significantly $(P<0.05)$ decreased by resveratrol at $5 \mu \mathrm{M}$ or above (Fig. 1). The expression of CYP1A1 and CYP1B1 was induced by DMBA by about 115 - and $6 \cdot 2$-fold, respectively $(P<0 \cdot 05)$. Resveratrol at $1 \mu \mathrm{M}$ significantly reduced CYP1A1 expression

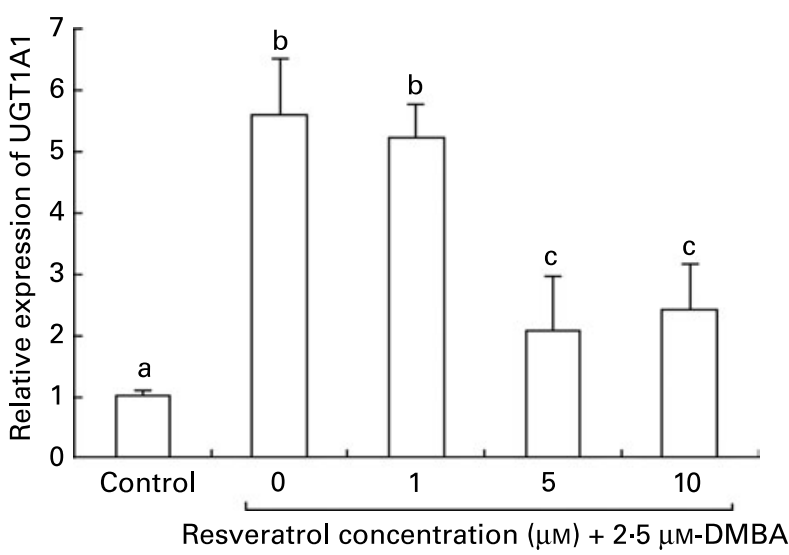

Fig. 1. Effect of resveratrol on 7,12-dimethylbenz[a]anthracene (DMBA)induced UDP-glucuronosyltransferase (UGT) 1A1 expression. MCF-10A cells were treated with $2.5 \mu \mathrm{M}$-DMBA and resveratrol and cultured for $24 \mathrm{~h}$. mRNA expression of UGT1A1 was quantified by real-time PCR. Values are means ( $n$ 3), with standard deviations represented by vertical bars. One-way ANOVA revealed that means are significantly $(P<0.05)$ different, and post hoc ranking testing indicated that $\mathrm{b}>\mathrm{c}>\mathrm{a}$. 
by $45 \%$ of cultures induced by DMBA only (Fig. 2), while $5 \mu \mathrm{M}$-resveratrol reduced CYP1B1 expressions by $40 \%$ in the DMBA-induced cultures $(P<0 \cdot 05)$ (Fig. 3).

Resveratrol reduced 7,12-dimethylbenz[a ]anthracene-induced ethoxyresorufin-O-deethylase activities

DMBA induced ethoxyresorufin- $O$-deethylase activity by $3 \cdot 4$ fold $(P<0.05)$. Figure 4 showed that $1 \mu \mathrm{M}$-resveratrol reduced the ethoxyresorufin- $O$-deethylase activity by $52 \%(P<0 \cdot 05)$ of the DMBA-induced samples. Resveratrol at 5 and $10 \mu \mathrm{M}$ further reduced DMBA-induced ethoxyresorufin- $O$-deethylase activity.

Resveratrol reduced the binding of 7,12-dimethylbenz[a ] anthracene-DNA in MCF-10A cells

DMBA could intercalate DNA and caused DNA damage. Figure 5 shows that resveratrol could also reduce the chelation of DMBA metabolites to DNA in MCF-10A cells; $1 \mu \mathrm{M}-$ resveratrol could reduce DNA adduct formation by $20 \%$ while 5 and $10 \mu \mathrm{M}$-resveratrol could reduce the formation by $40 \%$ of the cultures treated with DMBA only $(P<0 \cdot 05)$.

\section{Resveratrol moderated DNA strand breakage generated by 7,12-dimethylbenz[a ]anthracene in MCF-10A cells}

Treatment with DMBA increased the score from 0 to 1 by the visual scoring procedure. When these cells were simultaneously co-treated with 5 or $10 \mu \mathrm{M}$-resveratrol, the scores came down to 0.08 and 0.1 respectively (Fig. 6). Judging from the maximum scale of 4 , DNA damage caused by DMBA alone was significant but not extensive.

Effect of resveratrol on 7,12-dimethylbenz[a ]anthraceneinduced oxidative DNA damage

Flow cytometry showed that a right shift of fluorescence occurred upon 2.5 $\mu \mathrm{M}$-DMBA treatment with a 10 -unit increase

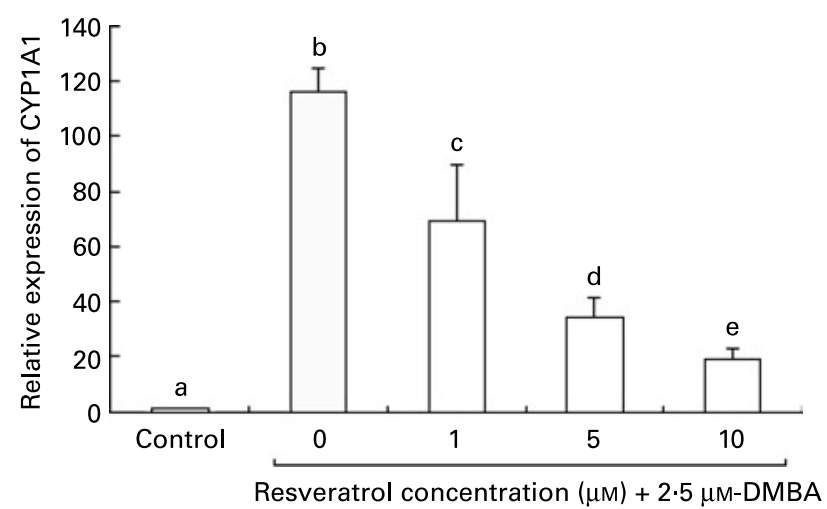

Fig. 2. Effect of resveratrol on 7,12-dimethylbenz[a]anthracene (DMBA)induced cytochrome P450 (CYP) 1A1 expression. MCF-10A cells were treated with $2.5 \mu \mathrm{M}$-DMBA and resveratrol and cultured for $24 \mathrm{~h}$. mRNA expression of CYP1A1 was quantified by real-time PCR. Values are means ( $n$ 3), with standard deviations represented by vertical bars. One-way ANOVA revealed that means are significantly $(P<0.05)$ different, and post hoc ranking testing indicated that $b>c>d>e>a$.

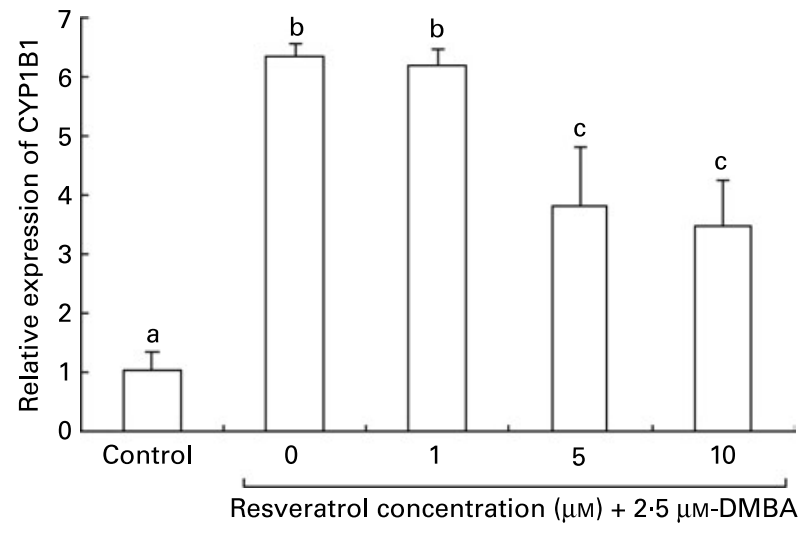

Fig. 3. Effect of resveratrol on 7,12-dimethylbenz[a]anthracene (DMBA)induced cytochrome P450 (CYP) 1B1 expression. MCF-10A cells were treated with $2.5 \mu \mathrm{M}-\mathrm{DMBA}$ and resveratrol and cultured for $24 \mathrm{~h}$. mRNA expression of CYP1B1 was quantified by real-time PCR. Values are means ( $n$ 3), with standard deviations represented by vertical bars. One-way ANOVA revealed that means are significantly $(P<0.05)$ different, and post hoc ranking testing indicated that $\mathrm{b}>\mathrm{c}>\mathrm{a}$.

in the Gmean (Fig. 7(A)), i.e. Gmean of control $=69(95 \%$ CI 63, 77); Gmean of DMBA $=79(95 \%$ CI 80, 105). This result indicated that the treatment increased the amount of 8-oxodG in DNA. The co-treatment of $0 \cdot 1,1$ and $10 \mu \mathrm{M}$-resveratrol did not revert the shifted fluorescence (Fig. 7(B)-(D)), i.e. the Gmeans of $0 \cdot 1,1$ and $10 \mu \mathrm{M}$-resveratrol co-treatment were 83 (95\% CI 73.7, 92.8), 96 (95\% CI 82.8, 111) and $92(95 \%$ CI 80, 103), respectively. Instead, the shift appeared to be increased after the co-treatment with 1 or $10 \mu \mathrm{M}$-resveratrol.

\section{Effect of 7,12-dimethylbenz[a ] anthracene and co-treatment of resveratrol on oxidative DNA repair}

Glycosylase activity is crucial in repairing DNA damage. In the DMBA-treated group, there was no indication of increased activity in 8-oxodG glycosylase compared with the control. In addition, administration of resveratrol at the dosages ranging from $0 \cdot 1$ to $10 \mu \mathrm{M}$ did not elevate the repairing capacity (data not shown). This result verified that resveratrol did not exercise any influence on oxidative DNA damage.

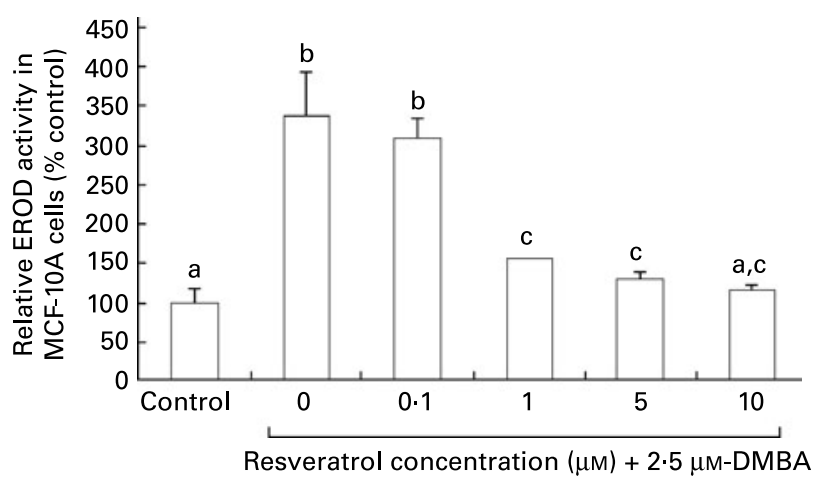

Fig. 4. Ethoxyresorufin-O-deethylase (EROD) activity in cells treated with resveratrol and 7,12-dimethylbenz[a]anthracene (DMBA). MCF-10A cells were seeded in ninety-six-well culture plates and treated with $2.5 \mu \mathrm{M}-\mathrm{DMBA}$ and resveratrol. After a $24 \mathrm{~h}$ treatment, the cells were assayed for EROD activity. Values are means ( $n 3)$, with standard deviations represented by vertical bars. One-way ANOVA revealed that means are significantly $(P<0.05)$ different, and post hoc ranking testing indicated that $\mathrm{b}>\mathrm{c}>\mathrm{a}$. 


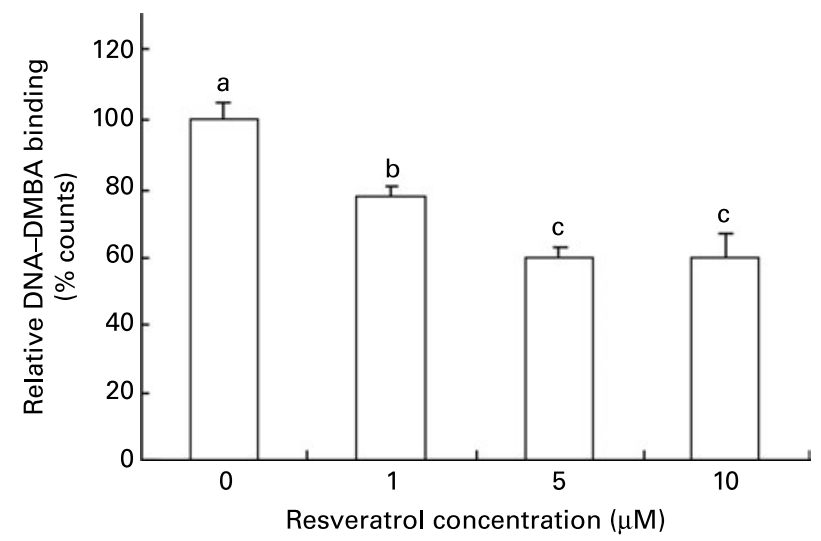

Fig. 5. Reduction in 7,12-dimethylbenz[a] anthracene (DMBA)-DNA binding by resveratrol treatment. MCF-10A cells were seeded in six-well culture plates and treated with resveratrol and ${ }^{3} \mathrm{H}$-labelled DMBA. After a $24 \mathrm{~h}$ treatment, genomic DNA was extracted and the DMBA-DNA lesions were determined by scintillation counting. Values are means $(n 3)$, with standard deviations represented by vertical bars. One-way ANOVA revealed that means are significantly $(P<0.05)$ different, and post hoc ranking testing indicated that $\mathrm{a}>\mathrm{b}>\mathrm{c}$.

\section{Discussion}

Previous studies have shown the inhibitory effect of resveratrol on CYP1 at the enzyme level ${ }^{(21,34)}$. In the present study, we demonstrated that the expression of these enzymes was suppressed in the transformed breast cell line MCF-10A. Furthermore, the capacity of resveratrol to alleviate $\mathrm{PAH}$-induced DNA damage and suppress the phase II enzyme UGT1A1 was shown for the first time.

In the present study, we also showed for the first time that resveratrol could reduce DNA damage induced by DMBA. Reduced chelation of DMBA to DNA appeared to be the major route for protection, because the amount of 8-oxodG induced by the PAH was not altered by resveratrol. Inhibition

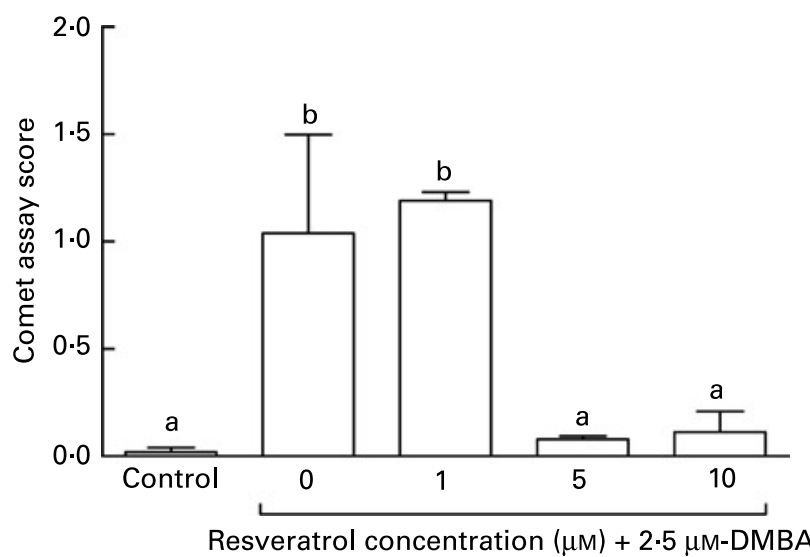

Fig. 6. Comet-forming activity in cells treated with 7,12-dimethylbenz[a] anthracene (DMBA) and resveratrol. MCF-10A cells were seeded in six-well culture plates and treated with $2.5 \mu \mathrm{M}$-DMBA and resveratrol. After a $72 \mathrm{~h}$ treatment, cells were disaggregated with trypsin and EDTA before incorporation into the comet assay as described in Materials and methods. Cells with a fragmented DNA tail were scored according to a five-point scale (0-4). Values are means $(n 3)$, with standard deviations represented by vertical bars. One-way ANOVA revealed that means are significantly $(P<0.05)$ different, and post hoc ranking testing indicated that $\mathrm{b}>\mathrm{a}$. of the formation rather than facilitation of elimination of the carcinogen seems most likely since the expression of both CYP1A1/1B1 and UGT1A1 was suppressed.

The comet assay revealed that resveratrol offered a protective effect on DNA integrity against DMBA assault in the present study. As reviewed by Xue \& Warshawsky ${ }^{(35)}$, PAH may induce multifaceted DNA damage. It can be metabolised into isomers of diol-epoxide and radical cations. These diol-epoxides and radical cations of PAH may bind to DNA and form adducts. In addition, PAH-o-quinone and reactive oxygen species may also be generated in an alternative metabolic pathway. The CYP enzymes, CYP1A1, 1B1 and $1 \mathrm{~A} 2$, are responsible for generating some of those proximate carcinogens. CYP1A1 and 1B1 are predominantly expressed in extrahepatic tissues, including the breast. Similar to a previous study on dioxin ${ }^{(36)}$, resveratrol in the present investigation could suppress the expression of CYP1A1 and CYP1B1 induced by DMBA in the non-tumorigenic MCF-10A cells. As the initial steps of diol-epoxide metabolism required CYP1 enzymes, decreased CYP1 expression could produce a lesser amount of diol-epoxides, reducing DNA damage as resveratrol concentration increases.

Cellular DNA may also be damaged by oxidative stress. Oestrogen has been demonstrated to induce oxidative DNA damage in breast cells ${ }^{(32,37)}$, and resveratrol administration can alleviate this damage. The phytocompound can also protect against other oxidative DNA damage-causing agents, such as 3-morpholinosydnomine $N$-ethylcarbamide ${ }^{(38)}$, $\mathrm{H}_{2} \mathrm{O}_{2}^{(39,40)}$ and ethanol ${ }^{(41)}$ in other cell types. In contrast, resveratrol did not reduce the DMBA-induced oxidative damage in the present study. A different pathway of the generation of oxidative DNA damage could undermine the influence of resveratrol in the present study. However, the present results agreed with a study which illustrated the pro-oxidative nature of resveratrol in human lymphocytes ${ }^{(42)}$.

A previous study has shown that the phase II enzyme UGT1A1 can protect against PAH-induced DNA damage in breast cells ${ }^{(20)}$. However, the induced UGT1A1 expression was suppressed by resveratrol in the present study. Transcriptional control could be the underlying mechanism. Ciolino \& $\mathrm{Yeh}^{(21)}$ have shown that aryl hydrocarbon receptor activation can be suppressed by resveratrol. Since the gene promoter of UGT1A1 has xenobiotic response elements, the response of UGT1A1 expression was similar to that of the CYP1 enzymes.

Resveratrol has been proposed to be a potential chemopreventive agent against breast cancer. It can protect against DMBA- or $N$-methyl- $N$-nitrosourea-induced mammary tumorigenesis, and the protein expression of some downstream genes of oestrogen receptor transactivation is also altered ${ }^{(43)}$. The reduction in CYP1A1 expression and enzyme activity may contribute to the anti-initiation activities of resveratrol ${ }^{(21,44)}$. Moreover, resveratrol may interrupt the promotion or progression phase by inhibiting cyclo-oxygenase- $2^{(45)}$. Resveratrol's agonist/antagonist activity toward oestrogen receptor binding may contribute to the antagonism of oestradiol-induced MCF-7 cell growth, the expression of transforming growth factor $\alpha$, and insulin-like growth factor I receptor $^{(46)}$. The minimum concentration at which aromatase inhibition was observed in the present study was comparable with these studies. 

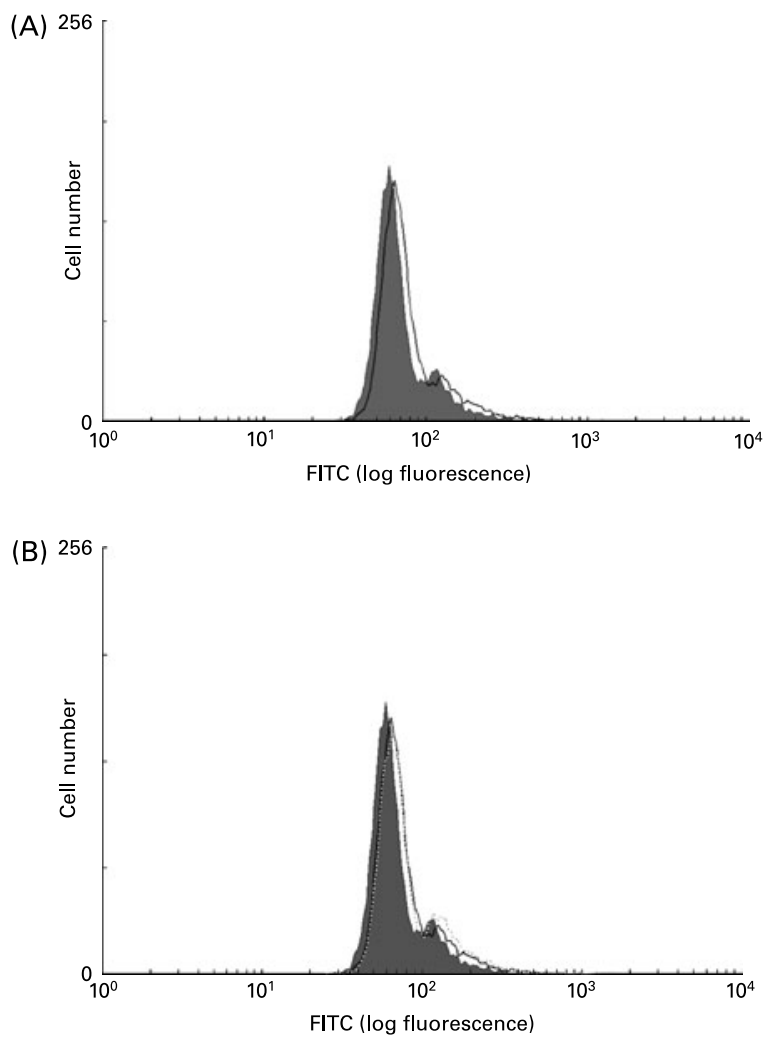
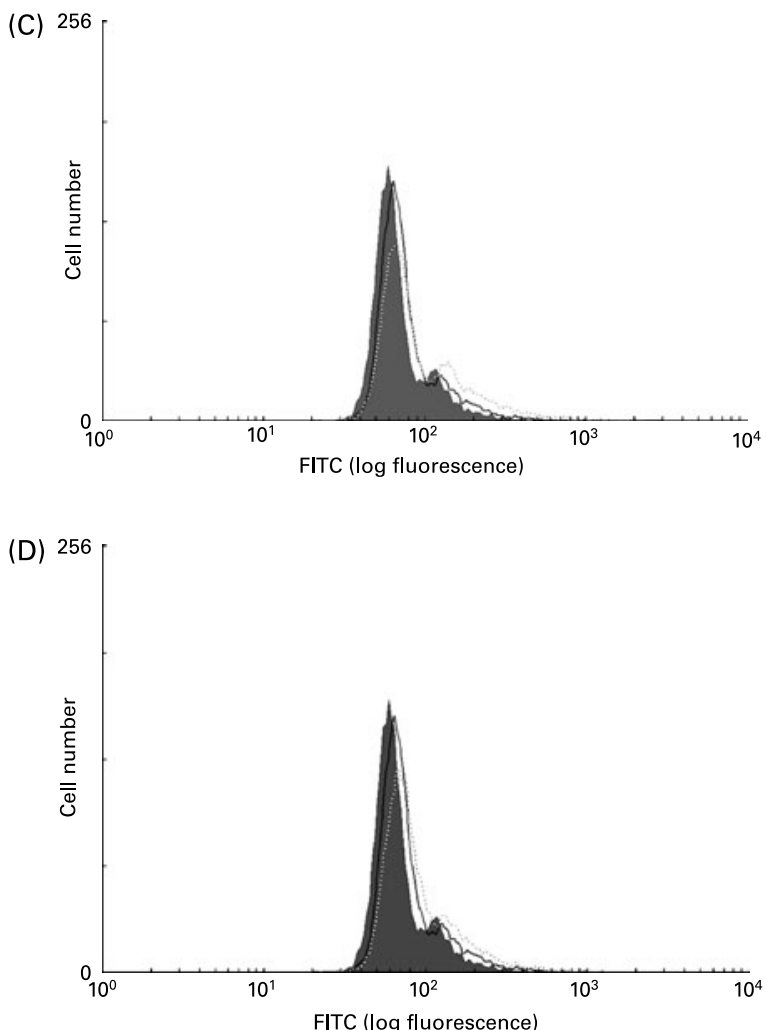

Fig. 7. Oxidative DNA damage in 7,12-dimethylbenz[a]anthracene (DMBA) and resveratrol co-treated MCF-10A cells. MCF-10A cells were seeded in six-well culture plates and treated with $2.5 \mu \mathrm{M}-\mathrm{DMBA}$ and resveratrol for $24 \mathrm{~h}$. Cells were disaggregated with trypsin and EDTA, fixed and processed for flow cytometry. (A) Control cells $(\square ;-)$ with oxidised DNA conjugated to fluorescein isothiocyanate (FITC). The conjugated profile of cells treated with DMBA (-) shifted to the right. (B) Resveratrol at $0.1 \mu \mathrm{M}(---)$ co-adminstrated in the culture. (C) Resveratrol at $1 \mu \mathrm{M}(---)$ co-adminstrated in the culture. (D) Resveratrol at $10 \mu \mathrm{M}(---)$ co-adminstrated in the culture. The geometric means (Gmeans) of control, DMBA treatment, DMBA-0.1 $\mu \mathrm{M}$-resveratrol co-treatment, DMBA-1 $\mu \mathrm{M}$-resveratrol co-treatment and DMBA-10 $\mu \mathrm{M}$-resveratrol co-treatment are 69, 79, 83, 96 and 92 units of light intensity, respectively. This set of distribution diagrams represents one of three independent experiments.

Regarding the timing of treatment, pre-treating cells with resveratrol for $6 \mathrm{~h}$ before DMBA administration would have a comparable CYP1 enzyme suppression (data not shown). This suggests that resveratrol consumed before or during PAH exposure would have a protective effect.

In summary, we demonstrated that DNA damage induced by PAH was reduced by the red wine polyphenol resveratrol in a non-cancerous breast cell line in the present study. However, the phytochemical also suppressed the phase II enzyme UGT1A1 and did not up-regulate the oxidative DNA repair system. Ultimately, inhibition of the phase I enzyme rather than reducing oxidative DNA damage was the potential chemoprevention mechanism of resveratrol on $\mathrm{PAH}$-induced genotoxicity.

\section{Acknowledgements}

This project was funded by the Chinese University of Hong Kong.

H. Y. L performed most of the experiments and statistical analysis; L. H. Y. helped to complete some of the project experiments; S. G. and A.-L. L. did the DNA repair assays; L. K. L. contributed to the idea generation and coordination of this project.

There is no conflict of interest associated with the present study.

\section{References}

1. International Agency for Research on Cancer (1983) Polynuclear Aromatic Compounds, Part 1. Chemical, Environmental and Experimental Data. IARC Monographs on the Evaluation of the Carcinogenic Risk of Chemicals to Humans, vol. 32. Lyon, France: International Agency for Research on Cancer.

2. Li D, Wang M, Dhingra K, et al. (1996) Aromatic DNA adducts in adjacent tissues of breast cancer patients: clues to breast cancer etiology. Cancer Res 56, 287-293.

3. Dertinger SD, Lantum HB, Silverstone AE, et al. (2000) Effect of 30-methoxy-40-nitroflavone on benzo[ $a$ ]pyrene toxicity. Aryl hydrocarbon receptor-dependent and -independent mechanisms. Biochem Pharmacol 60, 189-196.

4. Safe S (2001) Molecular biology of the Ah receptor and its role in carcinogenesis. Toxicol Lett 120, 1-7.

5. Shimizu Y, Nakatsuru Y, Ichinose M, et al. (2000) Benzo[a $]$ pyrene carcinogenicity is lost in mice lacking the aryl hydrocarbon receptor. Proc Natl Acad Sci U S A 97, 779-782.

6. Buters JT, Sakai S, Richter T, et al. (1999) Cytochrome P450 CYP1B1 determines susceptibility to 7, 12-dimethylbenz $[a]$ anthracene-induced lymphomas. PNAS 96, 1977-1982.

7. Keshavaa C, Divib RL, Whipkeya DL, et al. (2005) Induction of CYP1A1 and CYP1B1 and formation of carcinogen-DNA adducts in normal human mammary epithelial cells treated with benzo[ $a$ ]pyrene. Cancer Lett 221, 213-224.

8. Iscan M, Klaavuniemi T, Coban T, et al. (2001) The expression of cytochrome P450 enzymes in human breast tumours and normal breast tissue. Breast Cancer Res Treat 70, 47-54. 
9. Modugno F, Knoll C, Kanbour-Shakir A, et al. (2003) A potential role for the estrogen-metabolizing cytochrome P450 enzymes in human breast carcinogenesis. Breast Cancer Res Treat 82, 191-197.

10. Lehmann L \& Wangner J (2008) Gene expression of $17 \beta$-estradiol-metabolizing isozymes: comparison of normal human mammary gland to normal human liver and to cultured human breast adenocarcinoma cells. Adv Exp Med Biol 617, 617-624.

11. MacDonald CJ, Ciolino HP \& Yeh GC (2001) Dibenzoylmethane modulates aryl hydrocarbon receptor function and expression of cytochromes P50 1A1, 1A2, and 1B1. Cancer Res 61, 3919-3924.

12. Kleiner HE, Vulimiri SV, Reed MJ, et al. (2002) Role of cytochrome P450 1A1 and 1B1 in the metabolic activation of 7,12-dimethylbenz $[a]$ anthracene and the effects of naturally occurring furanocoumarins on skin tumor initiation. Chem Res Toxicol 15, 226-235.

13. Taioli E (1999) International collaborative study on genetic susceptibility to environmental carcinogens. Cancer Epidemiol Biomarkers Prev 8, 727-728.

14. Zheng W, Xie DW, Jin F, et al. (2000) Genetic polymorphism of P450 1B1 and risk of breast cancer. Cancer Epidemiol Biomarkers Prev 9, 147-150.

15. Hum DW, Belanger A, Levesque E, et al. (1999) Characterization of UDP-glucuronosyltransferases active on steroid hormones. J Steroid Biochem Mol Biol 69, 413-423.

16. Kuuranne T, Kurkela M, Thevis M, et al. (2003) Glucuronidation of anabolic androgenic steroids by recombinant human UDP-glucuronosyltransferases. Drug Metab Dispos $\mathbf{3 1}$ $1117-1124$

17. King CD, Green MD, Rios GR, et al. (1996) The glucuronidation of exogenous and endogenous compounds by stably expressed rat and human UDP-glucuronosyltransferase 1.1. Arch Biochem Biophys 332, 92-100.

18. Tukey RH \& Strassburg CP (2000) Human UDP-glucuronosyltransferases: metabolism, expression, and disease. Аппи Rev Pharmacol Toxicol 40, 581-616.

19. Burchell B (2003) Genetic variation of human UDP-glucuronosyltransferase: implications in disease and drug glucuronidation. Am J Pharmacogenomics 3, 37-52.

20. Leung HY, Wang Y \& Leung LK (2007) Differential effect of over-expressing UGT1A1 and CYP1A1 on xenobiotic assault in MCF-7 cells. Toxicology 242, 153-159.

21. Ciolino HP \& Yeh GC (1999) Inhibition of aryl hydrocarbon induced cytochrome P-450 1A1 enzyme activity and CYP1A1 expression by resveratrol. Mol Pharmacol 56, 760-767.

22. Aziz MH, Kumar R \& Ahmad N (2003) Cancer chemoprevention by resveratrol: in vitro and in vivo studies and the underlying mechanisms (review). Int J Oncol 23, 17-28.

23. Levi F, Pasche C, Lucchini F, et al. (2005) Resveratrol and breast cancer risk. Eur J Cancer Prev 14, 139-142.

24. Simopoulos AP (2004) The traditional diet of Greece and cancer. Eur J Cancer Prev 13, 219-230.

25. Zientek-Targosz H, Kunnev D, Hawthorn L, et al. (2008) Transformation of MCF-10A cells by random mutagenesis with frameshift mutagen ICR191: a model for identifying candidate breast-tumor suppressors. Mol Cancer 7, 51.

26. Chan HY \& Leung LK (2003) A potential protective mechanism of soya isoflavones against 7,12-dimethylbenz $[a]$ anthracene tumour initiation. Br J Nutr 90, 457-465.

27. Forchhammer L, Brauner EV, Folkmann JK, et al. (2008) Variation in assessment of oxidatively damaged DNA in mononuclear blood cells by the comet assay with visual scoring. Mutagenesis 23, 223-231.
28. Livak KJ \& Schmittgen TD (2001) Analysis of relative gene expression data using real-time quantitative PCR and the $2^{-\Delta \Delta \mathrm{CT}}$ method. Methods 25, 402-408.

29. Leung HY, Yung LH, Poon CH, et al. (2008) Genistein protects against polycyclic aromatic hydrocarbon-induced oxidative DNA damage in non-cancerous breast cells MCF-10A. $\mathrm{Br} \mathrm{J}$ Nutr 101, 257-262.

30. Lu A-L, Yuen DS \& Cillo J (1996) Catalytic mechanism and DNA substrate recognition of Escherichia coli MutY protein. J Biol Chem 271, 24138-24143.

31. Lu A-L (2000) Repair of A/G and A/8-oxoG mismatches by MutY adenine DNA glycosylase. In DNA Repair Protocols, pp. 3-16 [P Vaughan, editor]. Totowa, NJ: Humana Press.

32. Lu A-L, Tsai-Wu JJ \& Cillo J (1995) DNA determinants and substrate specificities of Escherichia coli MutY. J Biol Chem 270, 23582-23588.

33. Hazra TK, Izumi T, Maidt L, et al. (1998) The presence of two distinct 8-oxo-guanine repair enzymes in human cells: their potential complementary roles in preventing mutation. Nucleic Acids Res 26, 5

34. Chang TK, Chen J \& Lee WB (2001) Differential inhibition and inactivation of human CYP1 enzymes by trans-resveratrol: evidence for mechanism-based inactivation of CYP1A2. J Pharmacol Exp Ther 299, 874-882.

35. Xue W \& Warshawsky D (2005) Metabolic activation of polycyclic and heterocyclic aromatic hydrocarbons and DNA damage: a review. Toxicol Appl Pharmacol 206, 73-93.

36. Chen ZH, Hurh YJ, Na HK, et al. (2004) Resveratrol inhibits TCDD-induced expression of CYP1A1 and CYP1B1 and catechol estrogen-mediated oxidative DNA damage in cultured human mammary epithelial cells. Carcinogenesis 25, 2005-2013.

37. Bianco NR, Chaplin LJ \& Montano MM (2005) Differential induction of quinone reductase by phytoestrogens and protection against oestrogen-induced DNA damage. Biochem $J$ 385, 279-287.

38. Moon HK, Yang ES \& Park JW (2006) Protection of peroxynitrite-induced DNA damage by dietary antioxidants. Arch Pharm Pres 29, 213-217.

39. Quincozes-Santos A, Andreazza AC, Nardin P, et al. (2007) Resveratrol attenuates oxidative-induced DNA damage in C6 glioma cells. Neurotoxicology 28, 886-891.

40. Ungvari Z, Orosz Z, Rivera A, et al. (2007) Resveratrol increases vascular oxidative stress resistance. Am J Physiol Heart Circ Physiol 292, H2417-H2424.

41. Guo L, Wang LH, Sun B, et al. (2007) Direct in vivo evidence of protective effects of grape seed procyanidin fractions and other antioxidants against ethanol-induced oxidative DNA damage in mouse brain cells. J Agric Food Chem 55, 5881-5891

42. Azim AS, Bhat SH, Hanif S, et al. (2006) Plant polyphenols mobilize endogenous copper in human peripheral lymphocytes leading to oxidative DNA breakage: a putative mechanism for anticancer properties. FEBS Lett 580, 533-558.

43. Bhat KP, Lantvit D, Christov K, et al. (2001) Estrogenic and antiestrogenic properties of resveratrol in mammary tumour models. Cancer Res 61, 7456-7463.

44. Lee JE \& Safe S (2001) Involvement of a post-transcriptional mechanism in the inhibition of CYP1A1 expression by resveratrol in breast cancer cells. Biochem Pharmacol 62, 1113-1124.

45. Subbaramaiah K, Chung WJ, Michaluart P, et al. (1998) Resveratrol inhibits cyclooxygenase-2 transcription and activity in phorbol ester-treated human mammary epithelial cells. J Biol Chem 273, 21875-21882.

46. Lu R \& Serrero G (1999) Resveratrol, a natural product derived from grape, exhibits antiestrogenic activity and inhibits the growth of human breast cancer cells. J Cell Physiol 179, 297-304. 